\title{
Timing of transfer for pregnant women from Queensland Cape York communities to Cairns for birthing
}

\author{
Joanna L Arnold, Caroline M de Costa and Paul W Howat
}

$I^{2}$ n Far North Queensland, pregnant women from Cape York communities are obliged to travel to Cairns for late pregnancy and intrapartum care. Although some communities have onsite midwives and doctors, there are no facilities for birthing in the remote areas or regional centres. Women travel to Cairns at about 36 weeks' gestation and await birth.

The Cairns Health District catchment area is greater than the size of Victoria and has a population approaching 250000 (including Cairns). The Cape York communities usually have at least one midwife to provide routine antenatal care. The Royal Flying Doctor Service general practitioners visit all communities and provide important services, such as early dating scans and timely referral of women with high-risk pregnancies.

In 1991, specialist services were introduced to the Cape communities as the Far North Regional Obstetric and Gynaecological Service (FROGS). ${ }^{1}$ Specialist staff and registrars from Cairns Base Hospital $(\mathrm{CBH})$ travel to eight of the Cape communities four to six times per year. Since 2006, outreach midwives have accompanied the FROGS teams. After transfer to Cairns, women attend the Outreach Antenatal Clinic, which is staffed by the same midwives and, where possible, are cared for in labour by one of the Outreach team to provide continuity of care.

In the time that FROGS has been operating, the perinatal mortality rate for infants of Indigenous women in the region has decreased. In 1990, the perinatal mortality rate for Indigenous births in Queensland was 28 per 1000 births; in 2006, it was 20.3/1000 for Aboriginal births and 12.6/ 1000 for Torres Strait Islander births. ${ }^{2,3}$ Unpublished data from $\mathrm{CBH}$ show a perinatal mortality rate of $15 / 1000$ for births among Indigenous women from the Cape York region in 2006

Despite these improved outcomes, separation from family, financial stress while living in Cairns and negotiating the unfamiliar urban environment are some difficulties women face in this waiting period. We aimed to determine whether the timing of transfer at 36 weeks of gestation is medically appropriate, or whether it might be possible to make this transfer later in pregnancy.

\section{ABSTRACT}

Objective: To determine whether the current planned transfer of pregnant women from Cape York communities to Cairns at 36 weeks' gestation for birthing is medically appropriate.

Design and setting: Retrospective audit of travel details and demographic and obstetric outcome data on all women from Cape York communities who travelled to Cairns for late pregnancy care and birth at Cairns Base Hospital in 2006.

Main outcome measures: Length of stay in Cairns; gestational age at birth.

Results: In 2006, 172 women from 14 Cape communities travelled to Cairns to give birth. Of these, $76 \%$ identified as Aboriginal or Torres Strait Islander, 20\% as Caucasian and $4 \%$ were from other ethnic groups. The mean time of stay in Cairns before birth (range) was 24 (0-86) days. Eleven women (6\%) gave birth between 36 and 37 weeks of pregnancy; this point marked the beginning of a significant rise in births for increasing gestational ages.

Conclusion: Aiming for 36 weeks' gestation for transfer is medically appropriate, but results in long periods of separation of women from Cape communities from family and friends, with detrimental social, cultural and financial consequences. Reopening maternity units in towns serving the Cape communities could reduce the number of women from the region having to travel to Cairns for pregnancy care and birth.

MJA 2009; 190: 594-596

\section{METHODS}

An audit was performed of the case notes of all pregnant women who travelled from Cape York communities to give birth at $\mathrm{CBH}$ during 2006. Records were examined retrospectively by one of us (JLA). Data were entered into an Excel (Microsoft, Redmond, Wash, USA) spreadsheet.

Women from Cape communities were identified from information provided by the Clinical Benchmarking Unit of CBH. Demographic details, including age, parity, ethnicity and estimated date of confinement, were extracted from the women's case notes. The estimated date of confinement was calculated from the date of the first day of the last menstrual period when known, and/or the earliest dating scan.

Length of stay in Cairns was determined by comparing gestational age at transfer with gestational age at birth. The date of arrival in Cairns was either the first antenatal clinic appointment attended or the actual travel date taken from $\mathrm{CBH}$ Travel Office records.

Relevant obstetric history, including date of the child's birth, mode of delivery and any complications of pregnancy or birth were collected from the women's records.
In addition, information regarding any unplanned births that occurred within the communities was collated by contacting the Director of Nursing in each community.

Ethics approval for the audit was granted by the Cairns and Hinterland Health Service District Human Research Ethics Committee.

\section{RESULTS}

During the study period, 172 women were transferred from 14 Far North Queensland communities (Box 1). This represented 7.4\% of births at $\mathrm{CBH}$ (total births, 2328). Most women were Aboriginal (119; 69.2\%) or Caucasian $(34 ; 19.8 \%)$, with a minority from the Torres Strait Islands (12; 7.0\%), Asia (5; 2.9\%), and Papua New Guinea or New Zealand (2; $1.2 \%)$. The women's mean age (range) was 26.8 years ( $14.8-45.3$ years). The parity of the women ranged from zero to 12 . Onehundred and 30 women had an ultrasound for dating at or before 22 weeks' gestation.

For 55 women (31.9\%), the date of travel was known from accurate records. For the remainder, the date of the first antenatal appointment was used and their calculated length of stay is probably underestimated, as many women arrive in Cairns some days before their first appointment (Box 2). 


\begin{tabular}{lc}
1 Births among women from Cape \\
York communities, 2006 \\
Community & No. of births $(n=172)$ \\
\hline Aurukun & 22 \\
Bamaga & 13 \\
Coen & 7 \\
Cooktown & 32 \\
Hopevale & 15 \\
Kowanyama & 24 \\
Injinoo & 1 \\
Laura & 2 \\
Lockhart River & 19 \\
Mapoon & 2 \\
Napranum & 2 \\
Pormpuraaw & 6 \\
Weipa & 25 \\
Wujal Wujal & 2
\end{tabular}

Twenty-nine women were transferred before 34 weeks' gestation, mainly for complications of pregnancy. These included: threatened preterm labour (5); suspected or confirmed spontaneous rupture of membranes (4); intrauterine growth restriction or history of previous stillbirth (4); pre-eclampsia or hypertension (3); gestational diabetes (3); other medical problems (3); antepartum haemorrhage (1); and twin pregnancy (1); the reason was unrecorded for five women. However, of these 29 women, only four gave birth before 34 weeks' gestation.

All transfers that occurred after 34 weeks were for routine care. The latest transfer occurred at 39 weeks and 3 days. Most women gave birth after 36 weeks, with the mode value in the 39th week (ie, between 39 weeks and 39 weeks and 6 days [51 women, 29.7\%; Box 3]). Ten women (5.8\%) gave birth before 36 weeks, 11 (6.4\%) in the 36th week, 18 (10.5\%) in the 37th week, 35 (20.3\%) in the 38th week and 47 (27.3\%) after 40 weeks (Box 3). The average length of stay in Cairns was 24 days (range, 0-86 days) (Box 4).

Most women (120/172; 69.8\%) experienced normal vaginal births (Box 5). There were 27 emergency caesarean sections and 21 elective caesarean sections; the caesarean section rate was comparable to the background rate at $\mathrm{CBH}$. There were very few instrumental deliveries (two forceps, one vacuum extraction). There were 11 births in the communities; six of these were before 36 weeks' gestation. Four women were over 36 weeks' gestation and had decided not to move to Cairns. The remaining woman had received no antenatal care, so gestational age at birth was unknown.

\section{DISCUSSION}

We found that the 36th week of pregnancy is the beginning of a major rise in birth numbers $(6.4 \%$ of women gave birth in this week), thereby confirming that transfer to Cairns at 36 weeks is medically appropriate.

There were six preterm births in the communities before the planned transfer time. Currently, the paediatric retrieval team from $\mathrm{CBH}$ transfers preterm infants born outside the hospital to Cairns for care. In the current staffing environment in the Cape communities, women who remain in the communities after 36 weeks' gestation until birth may present problems for midwifery and medical staff who do not have obstetric training or obstetric and anaesthetic specialist backup available in the event of an emergency.

The wider issue is whether we are providing a satisfactory midwifery and obstetric service to the women in Cape York. There is much anecdotal evidence acquired from obstetric and midwifery practice in $\mathrm{CBH}$, and in the available literature, which suggests that the model of care involving transfer of women to a regional centre in late pregnancy for women living in remote communities may not be acceptable to the women or their health care workers. ${ }^{4-6}$ It is postulated that this is the reason that some women avoid presenting for antenatal care, as this will ultimately separate them from their support network later in the pregnancy. ${ }^{4}$ Similar findings have been reported from studies in south-western Queensland, the Indian Ocean Territories, Canada and rural Scotland. ${ }^{7-10}$ Feelings of isolation and loneliness, poor social support and significant financial hardship have been reported among Queensland women giving birth preterm in units geographically distant from their homes. ${ }^{7}$

There is a paucity of published work regarding obstetric care in Far North Queensland. A 1989 study that reported high rates of preterm labour and pregnancy and labour complications among Indigenous women also noted that women appreciated the safety of transfer to Cairns for delivery. ${ }^{5}$

Although perinatal outcomes are improving, there is undoubtedly considerable social and psychological stress associated with moving to Cairns to give birth. Women who travel to Cairns must stay in hostels or with relatives. They are often separated from the rest of their families for prolonged periods (Box 6). Only women 16 years of age or younger can have an escort funded to accompany them for support during their antenatal stay and labour (CBH Patient Travel Office Manager, personal communication). ${ }^{11}$ There are anecdotal reports of financial hardship, particularly when the woman's partner and family also stay in Cairns with limited financial support. Other concerns are the loss of customary cultural practices, decreased bonding with the father, and sibling jealousy due to the absence of the mother at this time. ${ }^{6}$

Midwives and GP-obstetricians face barriers if they wish to provide obstetric services
2 Timing of transfer of pregnant women from

Cape York communities, 2006

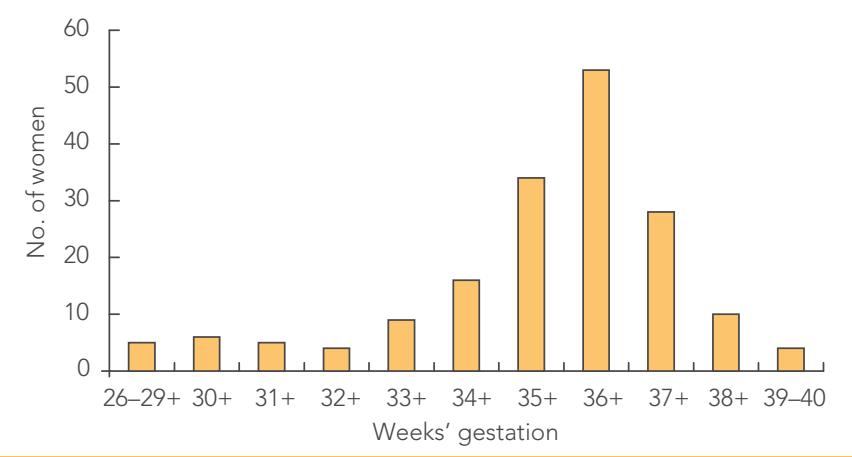

3 Timing of birthing for women from Cape York communities, 2006

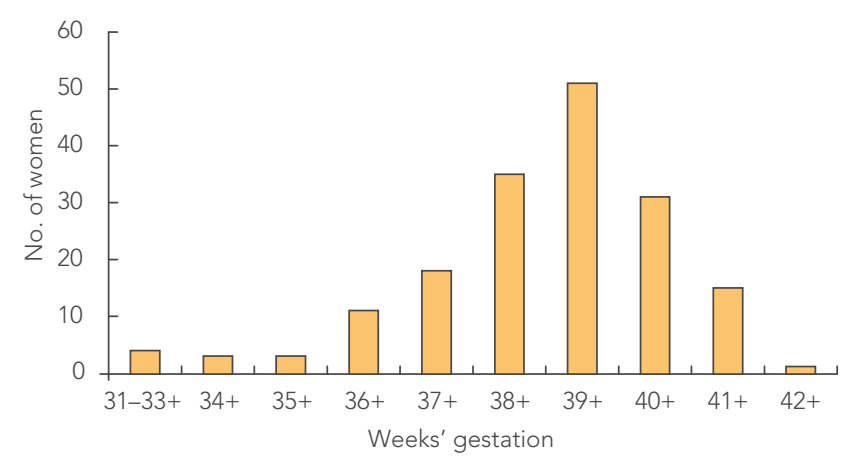


4 Length of stay in Cairns of pregnant women from Cape York communities, 2006

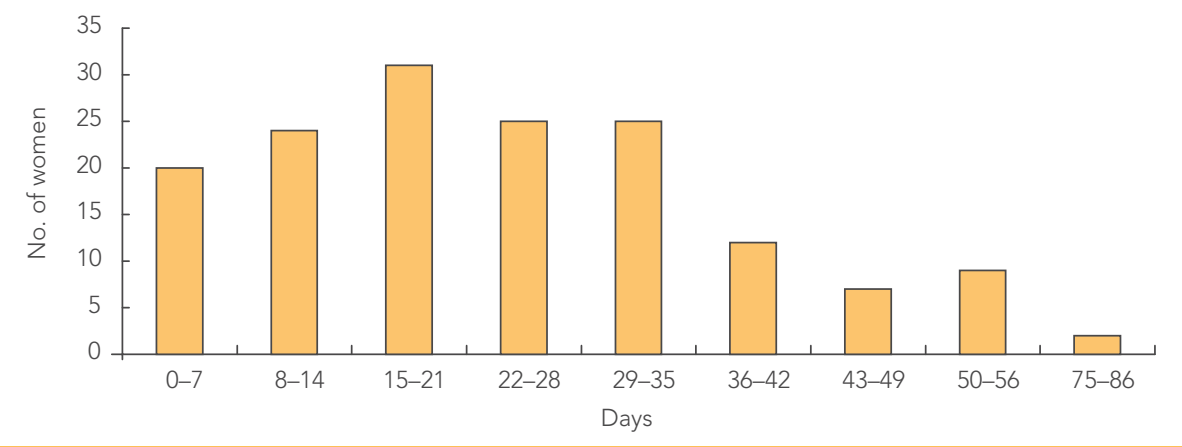

6 Case histories of pregnant women transferred to Cairns from Cape York communities, 2006

1. A 27-year-old woman was transferred to Cairns from a small community after developing mild hypertension at 35 weeks' gestation in her third pregnancy. Her first pregnancy had ended with an emergency caesarean section for fetal distress, but she had a vaginal birth on the second occasion, when she had been living in Brisbane. She was hoping for another vaginal birth, and her hypertension was well controlled. However, after 3 weeks on her own in a hostel in Cairns, with nightly phone calls from an increasingly stressed partner struggling to manage his job and two school-age daughters, she requested a repeat caesarean section at 39 weeks' gestation without her partner present. This was performed safely, but was clearly not this woman's preferred birth method.

2. A 23-year-old woman was transferred to Cairns at 30 weeks' gestation in her third pregnancy because of her history of two preterm births (at 31 and 32 weeks), and of postpartum haemorrhage requiring transfusion. The pregnancy continued uneventfully until 39 weeks, when induction of labour was performed, largely on social grounds - she was extremely concerned about her two children who remained with relatives and whose care she felt to be inadequate.

3. A 38-year-old woman with a history of two caesarean sections was required to transfer to Cairns in mid December and spend Christmas away from her family, including four school-age children, awaiting repeat caesarean section in early January.

in rural settings. These include constantly being on call and difficulty in maintaining skills. ${ }^{4} \mathrm{CBH}$ trains four doctors in advanced general practice obstetrics each year, but the declining numbers of GPs or salaried doctors with obstetric skills have long been in evidence in the medical workforce. ${ }^{12}$ There are not enough new midwives in training, and the midwifery workforce is an "ageing population". ${ }^{4}$ Little has been done to recruit or retain skilled doctors (either salaried doctors or private GPs) in these communities.

Until the late 1990s, Weipa and Cooktown hospitals provided maternity units in which women categorised as having low-risk pregnancies could receive antenatal and intrapartum care. Reopening these units with sufficient numbers of appropriately skilled GPs to provide obstetric and anaesthetic cover could impact positively on the provision of care for Cape York women, and hence further improve their pregnancy outcomes. Although some women judged to have highrisk pregnancies or who experience complications of pregnancy will continue to need transfer to Cairns for care, the numbers of women with low-risk pregnancies travelling could be greatly reduced, and women could birth at sites physically much closer to their homes and families. Further qualitative research into the opinions and experiences of women who stay in Cairns awaiting birth would be valuable to measure the impact on women, their families and their communities.

\section{ACKNOWLEDGEMENTS}

We thank Rose Hogan, James Cook University School of Medicine and Dentistry, and Lisa Gardiner, Clinical Benchmarking, $\mathrm{CBH}$, for their assistance in preparing this study.

\section{COMPETING INTERESTS}

None identified.

\section{AUTHOR DETAILS}

Joanna L Arnold, MB BS, FRANZCOG,

Obstetrician and Gynaecologist ${ }^{1}$

Caroline M de Costa, FRANZCOG, FRCOG,

$\mathrm{MPH}$, Professor of Obstetrics and

Gynaecology ${ }^{2}$

Paul W Howat, MB BS, FRANZCOG, Director of

Obstetrics and Gynaecology
5 Mode of delivery among women transferred from Cape York communities, 2006

\begin{tabular}{lc} 
Mode of delivery & No. $(\%)(n=172)$ \\
\hline Spontaneous vaginal birth & $120(69.8 \%)$ \\
Emergency LSCS & $27(15.7 \%)$ \\
Elective LSCS & $21(12.2 \%)$ \\
Forceps & $2(1.2 \%)$ \\
Vacuum delivery & $1(0.6 \%)$ \\
Twins vaginal birth & $1(0.6 \%)$ \\
\hline
\end{tabular}

LSCS = lower segment caesarean section

1 Cairns Base Hospital, Cairns, QLD.

2 Department of Obstetrics and Gynaecology, James Cook University, Cairns, QLD.

Correspondence: caroline.decosta@jcu.edu.au

\section{REFERENCES}

1 Humphrey MD, Dudgeon M, Smith WJ. FROGS - the development of a specialist outreach service. Aust Health Rev 1993; 16: 268-272.

2 Queensland Council on Obstetric and Paediatric Morbidity and Mortality. Trends in maternal, perinatal and paediatric mortality in Queensland. Brisbane: Queensland Health, 1995.

3 Queensland Health. Health Statistics Centre Perinatal Statistics 2006. Perinatal deaths. http:// www.health.qld.gov.au/hic/peri2006/Deaths.pdf (accessed Jun 2008).

4 Kildea S. Risk and childbirth in rural and remote Australia. 7th National Rural Health Conference: 2003 Mar 1-4; Hobart, Tas. http://nrha.ruralhealth.org.au/conferences/docs/7thNRHC/ Papers/refereed\%2010\%20papers/kildea.pdf (accessed Jun 2008).

5 Fitzpatrick J. Obstetric health services in Far North Queensland: is choice an option? Aust $J$ Public Health 1995; 19: 580-588.

6 Kildea S. Risky business: contested knowledge over safe birthing services for Aboriginal women. Health Sociol Rev 2006; 15: 387-396.

7 Smith M, Askew DA. Choosing childbirth provider location - rural women's perspectives. Rural Remote Health 2006; 6: 510. Epub 2006 Aug 23.

8 Roach SM, Downes S. Caring for Australia's most remote communities - obstetric services in the Indian Ocean Territories. Rural Remote Health 2007; 7: 699. Epub 2007 Apr 11.

9 Kornelsen J, Grzybowski S. The reality of resistance - the experiences of rural parturient women. J Midwifery Womens Health 2006; 51: 260-265.

10 Pitchforth E, Watson V, Tucker J, et al. Models of intrapartum care and women's trade-offs in remote and rural Scotland - a mixed-methods study. BJOG 2008; 115: 560-569.

11 Queensland Health. The patient travel subsidy scheme. Information for patients and their carers. http://www.health.qld.gov.au/services/community/ptss/www11399doc.pdf (accessed Apr 2009).

12 Innes K, Strasser RP. Why are general practitioners ceasing obstetrics [letter]? Med J Aust 1997; 166: 276-277.

(Received 17 Dec 2008, accepted 23 Mar 2009) 